\title{
O ESTIGMA NO ESPAÇO ESCOLAR: A PRÁTICA DOS CONSELHOS DE CLASSE
}

Paula Almeida de Castro ${ }^{1}$

\section{Resumo}

A estigmatização na interação entre professores e alunos no espaço escolar é o tema desse artigo. Neste, são apresentados os resultados das análises produzidas a partir da investigação etnográfica de uma escola pública de ensino fundamental na cidade do Rio de Janeiro. Para compreender as práticas escolares, orientadas pela relação professor e aluno, foi utilizada a observação participante nos espaços do Conselho de Classe e da sala de aula. Das análises realizadas depreendeu-se o fato de que, os alunos que não se encaixavam nos padrões normativos impostos pela escola, recebiam uma marca, ou seja, um estigma, passando a serem reconhecidos no meio escolar por tais atribuições. Foi identificado na fala dos professores um controle que tornava essa marca visível a todos que conviviam com esses alunos. Os resultados desse estudo fornecem pistas para a necessidade de serem repensadas as situações de vulnerabilidade e exclusão a que alguns alunos são expostos, principalmente nas avaliações dos Conselhos de Classe, em função de suas dificuldades nos processos educacionais. Oferecem, ainda, a possibilidade de pensar o respeito à diferença pela diferença em uma escola que se propõe efetivamente inclusiva.

Palavras-chave: Estigma; Controle; Corpo; Conselho de Classe; Etnografia.

\section{Introdução}

Neste estudo, a compreensão da experiência escolar, baseada na interação entre professor e aluno, considerou as relações vivenciadas no cotidiano escolar refletindo, direta ou indiretamente, na estigmatização e no controle dos corpos dos alunos. Cotidiano este,

\footnotetext{
${ }^{1}$ Psicóloga (PUC-Rio). Mestre e Doutora em Educação (ProPEd/UERJ). Pesquisadora associada do Núcleo de Etnografia em Educação. Atualmente é Professora visitante da Universidade estadual da Paraíba. E-mail: paulaalcastro@terra.com.br
}

Revista Reflexão e Ação, Santa Cruz do Sul, v.19, n2, p.158-172, jul./dez. 2011 
explorado a partir do resultado das análises de um estudo etnográfico desenvolvido em uma escola pública localizada na Zona Norte do município do Rio de Janeiro ${ }^{2}$. No período de um ano letivo (2006) foram realizadas visitas semanais à sala de aula e bimestralmente aos Conselhos de Classe utilizando a observação participante e o registro em áudio e vídeo. Cabe destacar que a observação dos Conselhos de Classe subsidiou o entendimento sobre as interações observadas na sala de aula, semanalmente, bem como os procedimentos adotados pelos professores junto a seus alunos no interior da mesma.

A etnografia, como abordagem teórico-metodológica nos estudos em Educação contribuiu, nesse estudo, de forma a desvelar as instâncias escolares que carecem de entendimento, tal como, as desigualdades e vulnerabilidades sócio-educacionais. À luz da etnografia, foi possível observar e analisar gestos, comportamentos e falas que ofereceram pistas para a compreensão sobre as práticas escolares, em especial, aquelas que estigmatizam os alunos, levando a que sejam associados a algum tipo de mazela educacional e social.

\section{Controlar para quê?}

Das análises realizadas, depreendeu-se o entendimento de que instâncias tanto psicológicas como físicas regiam o cotidiano daquela escola e sala de aula, atuando como mecanismos de controle e estigmatização sobre os alunos.

O conceito de controle utilizado, neste estudo, partiu dos pressupostos teóricos desenvolvidos por Foucault (1987, 1999, 2001 e 2003) e estigma, fomenta-se no estudo de Goffman (2005).

Por controle, entendem-se as estratégias utilizadas para monitorar, inspecionar e fiscalizar. Os espaços precisam ser vigiados e controlados de acordo com padrões normativos oriundos de uma sociedade que utiliza cada vez mais recursos tecnológicos de vigilância, tais como, câmeras, escutas e identificadores de chamada.

O termo controle, destacado por Revel (2005) na obra de Foucault, designa os mecanismos de vigilância que não servem exclusivamente para punir, mas também para corrigir e prevenir, tranformando-se em um tipo de "ortopedia social, para a qual o desenvolvimento da polícia e da vigilância das populações são os instrumentos essenciais"

\footnotetext{
${ }^{2}$ Os dados, apresentados neste artigo, integram o estudo de Castro (2006) revisados e ampliados. Resultados parciais deste estudo foram apresentados em eventos científicos nacionais.
}

Revista Reflexão e Ação, Santa Cruz do Sul, v.19, n2, p.158-172, jul./dez. 2011 
(REVEL, 2005, p.29). A autora acrescenta que “o controle social não está relacionado somente com a justiça, mas com poderes laterais que seriam as instituições psicológicas, psiquiátricas, criminológicas, médicas, pedagógicas” (REVEL, 2005, p.29).

O poder disciplinar envolve o uso de instrumentos de vigilância que atuam, de modo subliminar, no cotidiano escolar. Dentre os diversos instrumentos existentes, Foucault (1987) destaca: o olhar hierárquico, a sanção normalizadora e o exame. A aplicação de tais instrumentos e a adequação a eles pode ser observado, na maior parte do tempo, nas interações entre os profissionais da escola e os alunos. Sobre este contínuo processo de inspeção nos espaços escolares Foucault (1987) explica que;

As instituições disciplinares produziram uma maquinaria de controle que funcionou como um microscópio do comportamento; as divisões tênues e analíticas por elas realizadas formaram, em torno dos homens, um aparelho de observação, de registro e de treinamento (FOUCAULT, 1987, p. 145).

Neste sentido, a ideia da escola relacionada com um espaço para a aprendizagem é acrescida da utilização dos mecanismos de vigilância. Foucault (1987) relata a atividade pedagógica como "uma relação de fiscalização, definida e regulada, [que] está inserida na essência da prática do ensino: não como uma peça trazida ou adjacente, mas como um mecanismo que lhe é inerente e multiplica sua eficiência” (p.148).

A esta hierarquização escolar considerou-se, especificamente na escola estudada, a organização da gestão escolar. A coordenação pedagógica representava a figura central na determinação de regras na escola, juntamente com a vice-direção. A direção e os professores estariam no mesmo nível de tomada de decisão e, os alunos estariam no último plano apenas se adequando às decisões sancionadas. Esta hierarquia implicaria numa maquinaria de poder como menciona Foucault (2001).

Passou-se de uma tecnologia do poder que expulsa, que exclui, que bane, que marginaliza, que reprime, a um poder que é enfim um poder positivo, um poder que fabrica, um poder que observa, um poder que sabe e um poder que se multiplica a partir de seus próprios efeitos (FOUCAULT, 2001, p. 61).

As formas de exercício de controle, para a obtenção de uma vigilância estariam, portanto, ligadas às relações de poder em que elas implicam. Se o aluno sabe que seu comportamento está sendo avaliado pelo olhar do professor e, ainda, que será considerado no seu resultado final, ele permanecerá em sala de aula de forma que a professora o avalie positivamente.

Revista Reflexão e Ação, Santa Cruz do Sul, v.19, n2, p.158-172, jul./dez. 2011 
Foucault (1987) afirma que a vigilância assume um papel de supervisão direta do trabalho dos subordinados pelos superiores, assim como a execução da tarefa em sala de aula: os alunos sentam-se às mesas ou carteiras, normalmente dispostas em fileiras, todos em função do professor. Orientados fisicamente dessa forma, os alunos devem parecer alerta, ou então estarem absorvidos em seu trabalho. Entretanto, na prática, isso dependerá das habilidades do professor e das inclinações dos alunos no sentido de agirem de acordo com o que se espera deles.

As análises dos dados e o referencial teórico apontam que a escola e a sala de aula possuem um modelo quase ideal para o exercício da vigilância: a disposição das carteiras dos alunos e da mesa do professor é feita de modo a proporcionar o controle pelo olhar. É um diagrama de um poder que age pelo efeito de uma visibilidade geral (FOUCAULT, 1987). Foucault alude à estrutura física das salas de aula para salientar os mecanismos de vigilância utilizados. Ele explica que os velhos esquemas de encarceramento são substituídos pelos espaços vazios, as passagens, as janelas de vidro, entre outras formas de dar visibilidade ao interior dos ambientes fechados, como a sala de aula.

Pela utilização de tais mecanismos, o espaço escolar poderia ser considerado como local de aplicação de um controle rígido sob todo e qualquer desvio às normas estabelecidas, a saber, o cumprimento dos horários de saída e chegada à escola, a obrigatoriedade de permanecer em silêncio, sentados com "modos" e executando as tarefas. Desse modo, a escola estaria constituída por:

(...) uma micropenalidade do tempo (atrasos, ausências, interrupções das tarefas), da atividade (desatenção, negligência, falta de zelo), da maneira de ser (grosseria, desobediência), dos discursos (tagarelice, insolência), do corpo (atitudes "incorretas", gestos não conformes, sujeira), da sexualidade (imodéstia, indecência) (FOUCAULT, 1987, p.149).

A partir de tais considerações foi possível perceber a importância da estrutura física, bem como das diversas formas de vigilância para o exercício do controle e da estigmatização na escola e na sala de aula.

\section{Estigma: vulnerabilidade e exclusão}

A compreensão acerca do que venha a ser o estigma decorre dos padrões de normalidade vivenciados pelos indivíduos em sociedade. A normalidade pode ser expressa

Revista Reflexão e Ação, Santa Cruz do Sul, v.19, n2, p.158-172, jul./dez. 2011 
como a conformidade com um tipo de indivíduo que apresenta características em comum com outros indivíduos de sua sociedade, indicando a ausência de patologia e que acaba por configurar um padrão. Por outro lado, aquele que não é normal, ou seja, o anormal é aquele que escapa a este suposto padrão de normalidade, sendo apresentado à sociedade como um indivíduo que não se assemelha aos ditos normais.

Dessa forma, tudo o que apresenta características que não se assemelham aos ditos normais nos chamam a atenção. Quando um indivíduo depara-se com qualquer imagem que o choca, por suas características grotescas, estas causam estranhamento e toma-se tal imagem como um referencial de diferença. Passado o estranhamento inicial, procura-se manter esta imagem longe de nossos olhos, pois o que não é percebido como normal e semelhante não é aceito pelos padrões de normalidade daquele meio social. Tenta-se sempre tornar invisíveis cenas que desagradáveis. Isso pode ser visualizado, principalmente, nos grandes centros urbanos, quando andando pelas ruas, encontram-se pessoas doentes, com feridas expostas, apresentando a falta de membros dos corpos ou, até mesmo, pessoas usando roupas sujas e/ou rasgadas. Depara-se, todos os dias, com esse tipo de imagem que, embora cotidianas e evidentes, são por vezes ignoradas porque ferem o que é considerado normal. A estas imagens atribui-se a denominação de estigma.

Goffman (1978), explica que "o termo estigma foi criado pelos gregos para se referir a sinais corporais com os quais se procurava evidenciar alguma coisa de extraordinário ou mau sobre o status moral de quem os apresentava" (p.5). Assim os ladrões, escravos e traidores eram identificados em locais públicos pelas marcas feitas com fogo e mantidos à distância das pessoas moralmente aceitas pela sociedade. A partir desta perspectiva, pode-se inferir que as marcas feitas pela própria sociedade naqueles que fugiam a regra de conduta moral estabelecida, tornavam-se vítimas do estigma. A partir de então, o diferente, o que era marcado, passava a ser ignorado. Na contemporaneidade, esta marca possui outras características. Entende-se que sejam marcas oriundas do campo simbólico e que consideram não somente a diferença no corpo físico, mas as diferenças sociais de um modo geral. Nesse sentido, como salientado por Goffman (2005), o estigma se configura, ainda, como um mecanismo de exclusão.

Em Foucault (2002) encontram-se modelos de exclusão e controle relacionados com as doenças, tais como a lepra e a peste que, no final do século XVII e início do século 
XVIII, assolaram a Europa. Os indivíduos que possuíam algumas dessas doenças eram considerados perigosos para a sociedade e mantidos sob um rigoroso policiamento para que não contaminassem as pessoas saudáveis. Essa exclusão, como afirma Foucault, implicava a desqualificação do indivíduo (FOUCAULT, 2002, p.54). A expulsão era então substituída por este rigoroso policiamento e justificada como medida preventiva dentro da sociedade. Foucault (2002) explica que "não se trata de uma exclusão, trata-se de uma quarentena. Não se trata de expulsar, trata-se ao contrário de estabelecer, de fixar, de atribuir um lugar, de definir presenças controladas" (p.57). Foucault faz referência ao controle imposto àquele que ao ser considerado portador de alguma mazela, passa a ser monitorado para que não contamine outras pessoas com a doença que possui. A exclusão ocorre pela delimitação do espaço a ser ocupado pelos corpos estigmatizados tornando, assim, invisível à sociedade, o sujeito do estigma.

$\mathrm{Na}$ sociedade atual, a aparência denota essa característica própria do termo estigma e, retoma-se a definição de Goffman (2005), para salientar que a aparência é a primeira ideia que nos vem à mente quando pensamos em estigma. Entretanto, o estigma pode também estar relacionado ao comportamento, à fala ou aos modos de se vestir e viver. Tais aspectos causam estranheza e tende-se a excluir as pessoas que mantêm um modus vivendi avesso ao nosso. Dessa maneira criamos padrões de comportamento que, ao estarmos na presença de alguém, tentamos manter e espera-se que os outros também sigam tais padrões. E na escola? Como essas relações são evidenciadas?

\section{Escola: espaço de estigmatização?}

$\mathrm{Na}$ escola, tal como na sociedade, é possível visualizar essa repulsa ao diferente. Os alunos, quando não se encaixam nos padrões de normalidade impostos pelo sistema escolar, recebem uma marca, passando a serem reconhecidos no meio escolar por tais atribuições.

Nos conselhos de classe, observados nesse estudo, deparou-se com uma série de avaliações e julgamentos de professores sobre a capacidade de seus alunos. É importante destacar que os conselhos de classe são organizados com o objetivo de proporcionar uma análise, por parte dos professores e gestores, das ações pedagógicas em sala de aula. Das análises realizadas depreendeu-se que, nas falas de professores e gestores, a expressão de

Revista Reflexão e Ação, Santa Cruz do Sul, v.19, n2, p.158-172, jul./dez. 2011 
emoções negativas, a que Hargreaves (2004) se refere como sendo a economia emocional da exclusão social, estava relacionada tanto aos alunos quanto aos seus familiares. É entendimento comum que a participação da família na escola deveria criar um espaço de diálogo que auxiliasse na vida escolar do aluno. Contudo, percebeu-se que o contato com a família do aluno era utilizado como uma ferramenta de exclusão escolar. Os problemas familiares, quando evocados pelos professores nos Conselhos de Classe, eram utilizados como uma alternativa para identificar um culpado para as dificuldades escolares dos alunos. A questão "de quem é a culpa do fracasso escolar" ainda permeia as discussões, de um certo número de profissionais da Educação, que tendem a projetar toda e qualquer dificuldade encontrada no âmbito escolar para fatores externos a ele, prevalecendo, como na sabedoria popular de que o "Filho de peixe, peixinho é". Os professores associavam o comportamento dos filhos às atitudes e comportamento dos pais quando de sua ida à escola e, ainda, com os irmãos e demais parentes que estivessem matriculados na mesma.

Durante o segundo conselho de classe do ano, os professores falavam sobre o comportamento desviante de um determinado aluno que é justificado por uma professora pela seguinte fala: "A Porto da Pedra explica tudo". Diante de tal explicação, os outros professores reconheceram o aluno e os irmãos matriculados na mesma escola. Entretanto, uma professora percebeu que a pesquisadora não havia compreendido a fala da professora sobre Porto da Pedra e, então se prontificou a explicar o histórico dos alunos.

Ela explicou que a Porto da Pedra é uma escola de samba do Estado do Rio de Janeiro e que, em seu enredo de 1997 intitulado "No Reino da Folia cada louco com a sua mania", trazia uma ala - Ala camisa de força - com pessoas vestidas em camisas de força e cabelos desgrenhados. A referida professora comenta que o aluno e sua família guardavam uma estreita semelhança com os componentes da Ala camisa de força, por terem os cabelos desgrenhados e se vestirem com roupas velhas e rasgadas, complementando que apenas lhes faltava a camisa de força ${ }^{3}$. Abaixo, destaca-se o fragmento de fala no qual os participantes vão atribuindo estigmas diversos aos alunos, até identificarem de quem se tratava Beatriz, a aluna em avaliação no momento do Conselho de Classe.

Prof1: E a Beatriz...

Diretora: Irmã da Bruna?

Vice-diretora: não é a Gerciane... 402.

\footnotetext{
${ }^{3}$ Espécie de camisa de tecido forte, que envolve os braços e impede movimentos agressivos de indivíduos agitados.
}

Revista Reflexão e Ação, Santa Cruz do Sul, v.19, n2, p.158-172, jul./dez. 2011 
Prof1: Acho que é da sala delas (apontando para as professoras da 401 e da 402)

Diretora: não é irmã da Bárbara não?

Prof2: Quem que é irmã?

Prof1: é uma alta magrinha, moreninha...

Vice-diretora: A moreninha da 402.

Prof2: A Bárbara é minha.. será que é a minha Bárbara?

Continuam tentando descobrir o parentesco da aluna. Enquanto a prof1 fica folheando novamente o diário de classe

Vice-diretora: entrou a pouco tempo?

Diretora: Ah! Do Edmilson do Porto da Pedra...

Vice-diretora: Isso parente do Edmilson... Eles saíram daqui todos pequenos, ficaram um tempo fora e agora voltou tudo de novo.

As professoras comentam entre si rindo dos alunos.

Diretora: Jéssica, Bruna e Gustavo... Terceira série

Coordenadora: Porto da Pedra explica tudo...

Prof1: a gente olha pra ela... ela é maluca!

Coordenadora: não é?

Prof1: Ela caiu e bateu com a cabeça, a garota não vai, ela não engata a primeira.

Coordenadora: Olha só ser parente do Porto da Pedra já explica metade de todos os problemas dessa criança (rindo)

A prof1 tenta dar continuidade a avaliação da turma enquanto a Diretora, a vicediretora, coordenadora e outras professoras falam sobre a suposta loucura da mãe da aluna e ainda sobre o seu modo de se vestir e pentear.

Coordenadora: mas peraí o Porto da Pedra explica. Não teve um enredo logo no início sobre hospício? Que o povo vinha com o cabelo pintado de louro, aí Prof3 apelidou: é a componente da Porto da Pedra!

Vice-diretora: então até hoje (ri)

Prof3: aquela escola de samba que veio cheia de doido

Coordenadora: então foi...Ta vendo como eu lembro da história! Aí né a escola veio cheio de pessoal do Pinel, e tal...aí a Prof3 apelidou: aí ta vendo um componente da porto da pedra, escola de samba.

Durante a conversa, as professoras tentam identificar sem sucesso a aluna em questão. Inicialmente, pelo parentesco com outros alunos da escola, depois pela descrição física e de cor, ainda pela data de matrícula e, finalmente, pela marca atribuída ao irmão. Foi somente a partir de uma característica de loucura atribuída à família que foi possível avaliar a aluna. Ocorre que o aluno, ao receber tal atribuição, passa a ser reconhecido como tal e não mais com possibilidades de superação de sua realidade excludente.

Em todo momento, nesse conselho de classe, os participantes relacionam as características dos familiares com as condições precárias com que os alunos frequentam a escola. Os pais são, muitas vezes, identificados numa condição de inferioridade sem condição de proporcionar aos filhos recursos mínimos para que eles superem a condição de miséria em que nasceram e estão crescendo. Para essas professoras a herança cultural é fator preponderante para definir a experiência de fracasso dos alunos. 
Na pesquisa realizada por Hargreaves (2004) sobre as emoções no ensino, ele relata que os professores expressaram emoções negativas relacionadas aos pais de classe baixa, atribuindo a estes adjetivações do tipo "louco", "pirado", "dementes" ou "chorões" e, descreveram suas ações com verbos de contaminação quando os pais os "interrogavam", “desabafavam" com eles e "lhes atiravam" coisas na cara (HARGREAVES, 2004, p. 185). Esses verbos, nomeados por Hargreaves como de contaminação, expressavam desgosto e, tornaram-se meios pelos quais os professores mantinham a distância os pais de classe baixa ou de minorias.

Além da atribuição de fracassos à condição social dos alunos, em outro momento do Conselho de Classe, os professores associaram o comportamento de um dos familiares ao do aluno.

Coordenador pedagógico: mais olha só, veja pelo lado bom, quando você viu o pai com aquele comportamento, você entendeu porque a criança era daquele jeito né! Tudo se iluminou na sua cabeça. (Conselho de Classe, coordenadora pedagógica).

A alteração do pai descrita pelo coordenador pedagógico durante uma visita à escola contribuiu para o entendimento sobre o comportamento do aluno. A "iluminação" que a coordenação e a professora receberam com a visita do pai do aluno, foi utilizada para enquadrar o aluno na condição de incapaz em função de seus familiares. A escola, que deveria oferecer condições de superação, apenas atribui a causas externas os problemas de seus alunos sem novas possibilidades com a experiência escolar. O aluno, representado no fragmento de fala acima, foi entendido, em toda a sua dimensão, pelo comportamento apresentado pelo pai.

Segundo Lahire (2004), é comum atribuir aos alunos características derivadas das condições familiares e sociais, geralmente precárias, em que vivem, não promovendo a saída de seus filhos da situação de exclusão e vulnerabilidade social.

Justificar o" êxito escolar "de alguns alunos, aludindo à bagagem inicial de docência de suas famílias, serve para questionar claramente a" ideologia do dom "ao se pôr em evidência fenômenos de herança cultural, mas essa explicação não acrescenta nada em relação a essa bagagem docente inicial num dado momento da história da escola e nem aos métodos empregados para transmiti-la (LAHIRE, 2004, p.70).

Ao avaliar o aluno em sala de aula os professores acrescentam dados relacionados ao cotidiano da comunidade, à dinâmica e ao histórico familiar. Na maioria dos casos 
relatados, esses dados são utilizados para estigmatizar o aluno e reproduzir na escola a situação de miséria e vulnerabilidade em que vivem, inviabilizando o desenvolvimento social, cultural e acadêmico do aluno.

A capacidade ou incapacidade dos alunos é constantemente enfatizada pelos professores e gestores. A expectativa deles era a de que, a cada atividade proposta em sala de aula, todos fossem capazes de atendê-la prontamente. Ocorre que, estar em sala de aula, ou seja, incluído no espaço escolar, não significa que todos sejam iguais, mas que cada aluno, de forma diferenciada, tenha condições de aprender. Diante desse impasse, durante o Conselho de Classe, uma aluna foi considerada pela professora como preguiçosa pelo relato sobre o seu comportamento em sala de aula.

Prof1: Aí tem uma observação que eu coloquei lá porque a menina começa a faltar e a Aluna1 é aquela você sabe né, é aquela que quer que o mundo acabe em barranco pra ela morrer encostada...

Prof2:: preguiçosa né?

Prof1: se eu não ficar em cima dela o tempo todo sabe, faz isso e cobro não sei o que... ela não faz nada, nada, nada, nada, então eu coloquei lá que teve um dia que ela ficou enrolou, enrolou e ela é espertinha pra caramba esconde o caderno, guarda, ela é toda articulada nesse ponto ela é. Aí eu me estressei fui lá peguei o caderno e (faz o gesto de escrever com a mão) e falei que a mãe dela tinha que assinar, falei com a mãe dela ontem.

A professora aponta a preguiça da aluna para as atividades propostas, ao mesmo tempo em que ressalta a esperteza da mesma para tentar escapar da sala de aula. O controle à execução das tarefas e participação na sala de aula surge em forma de punição. Esta ocorre na atribuição de um número de faltas que poderão reprovar a aluna.

Em outro momento, nos Conselhos de Classe, foi possível observar a criação de um espaço de compartilhamento entre os professores sobre as situações vividas em sala de aula e a indecisão quanto ao destino a ser dado aos alunos. No fragmento de fala, apresentado abaixo, tal momento de compartilhamento no grupo é expresso pela professora que considera o aluno "chato" e de não saber "o que fazer com ele".

Coordenadora: Ele é muito chato. Eu vou compartilhar o sentimento com vocês. Prof ${ }^{a}$ Sheila: Ele é um dos piores. Quando até os piores estão fazendo o trabalho ele vai lá.(Nesse momento, professora continua a contar a história,a coordenadora e a diretora conversam baixo entre si, então a professora se dirige aos outros professores).

Prof ${ }^{\mathrm{a}}$ Sheila: $\mathrm{O}$ que eu vou fazer com ele?

Ao considerar o aluno como um dos piores da turma, a professora apenas atribui a ele uma característica de "ser chato" por seu comportamento impertinente. O mesmo não se 
detém apenas nas tarefas pedagógicas. A professora não chega a afirmar que o aluno não faz as tarefas, mas que ele circula pela sala conversando com os alunos que estão executando a tarefa. Durante as análises, quando comparada à descrição da professora sobre o comportamento do aluno no Conselho de Classe com a gravação da observação da sala de aula foi possível perceber que o aluno permanecia sentado, em silêncio e executando as tarefas propostas. Depois de certo tempo, ele passava a conversar com os alunos mais próximos, circulava pela sala ou solicitava permissão para ir ao banheiro ou beber água. Entretanto, a resposta para “O que eu vou fazer com ele?" foi abafada por conversas paralelas entre os outros participantes e, depois, abandonada pela professora Sheila. Sobre este aluno, fomos questionar a coordenação que explicou que apenas se tratava de um caso de "implicância dela [professora Sheila] com ele".

No terceiro Conselho de Classe do ano, evidenciou-se outra vertente da atribuição de anormalidade ao aluno, que é quando ele chega à escola com uma marca atribuída pela família. Entretanto, tratava-se de uma situação extraordinária, uma vez que, a coordenadora afirma ser esse o primeiro caso onde a escola considerava o aluno normal e a mãe atribuía a ele um déficit mental.

Coordenadora: É o primeiro caso que a escola tá dizendo que o aluno é normal, e a mãe diz que ele não é normal...o garoto é completamente normal, a única coisa que ele tem é porque é muito mimado, ele não consegue, ele ah sim, tudo que ele de repente perde o interesse de fazer ele para e vai fazer outra coisa que ele ta afim de fazer...e a mãe diz que todo mundo tem que ter paciência porque ele tem mentalidade de uma criança de um ano...só que ele vem aqui para a sala...né Solange, e faz os trabalhos, faz os textos, conversa normalmente, uma criança normal...Então para vocês sentirem como é que ta a nosso problema...

A família exerce na escola um papel fundamental na mediação entre o histórico de vida do aluno e a experiência escolar. $\mathrm{O}$ aluno traz consigo uma vivência familiar e social que podem ou não afetar o seu desempenho escolar. A tendência da escola em atribuir as causas do fracasso escolar a problemas externos, tal como a família, é recorrente no âmbito educacional. Ocorre que a família, em sua dinâmica, pode atribuir a um membro as características dos problemas vivenciados no interior da mesma. É o chamado bode expiatório. Na Psicologia Social (RODRIGUES; ASMAR; JABLONSKI, 2007) em situações de vivência de grupo, o bode expiatório (ou vítima expiatória) tem por função fazer recair sobre si os ataques que poderiam visar o líder ou o grupo na sua globalidade. Outra explicação é a da terapia de família de abordagem sistêmica onde o paciente 
designado preenche o papel de bode expiatório da família. A existência de uma vítima expiatória é um dos elementos reguladores do equilíbrio quase estacionário de um grupo ou homeostasia familiar (DORON; PAROT, 1998). Este indivíduo funcionaria como o depositário das doenças da família, sem que este tenha condições de sair da condição imposta a ele.

A escola o considera capaz pelo modo como avalia as potencialidades do aluno. Se ele possui capacidade de ler e escrever e desempenha suas tarefas na sala de aula significa que ele não possui problemas ou não carrega atribuições de estigma advindos das relações sociais e familiares.

\section{Comentários finais}

Nos dados apresentados, nesse artigo, destacou-se que a percepção de um professor a respeito de determinado aluno é acatada pelos demais em um processo que, em muitos casos, leva a estigmatização e a eminente exclusão escolar do mesmo, especialmente durante os Conselhos de Classe.

Nos Conselhos de Classe analisados, os professores, com frequencia, se reportam ao histórico comportamental, familiar e de saúde física e mental dos alunos, para ratificar a sua argumentação, na maioria dos casos negativa, com relação ao aluno. O discurso dos professores acaba por definir o futuro escolar de seus alunos que, na impossibilidade de superarem a realidade excludente, tornam-se vítimas do fracasso escolar.

Foi possível identificar, que o discurso e a prática funcionam de maneira excludente e que, apesar dos esforços de implementação de políticas pedagógicas que visam a criação de uma escola inclusiva, humanitária e voltada para o atendimento das necessidades educacionais de seus alunos, há ainda um longo caminho a ser percorrido. Caminho este, especialmente, relacionado aos processos de estigmatização nas avaliações escolares em geral.

Sobre as atribuições que acabam por estigmatizar o aluno, pode-se questionar sobre

os processos formativos de alunos e de professores. Ao professor é atribuída a responsabilidade de sentir-se parte da vida escolar, cumprir sua missão de ensinar, avaliar, incluir, promover e receber diariamente seus alunos com conhecimentos que deem conta de

Revista Reflexão e Ação, Santa Cruz do Sul, v.19, n2, p.158-172, jul./dez. 2011 
atender a adversidade na contemporaneidade. $\mathrm{O}$ aluno, por sua vez, deve estar apto para receber o que foi idealizado para ele. É neste cenário que as concepções de professores e alunos, sobre o que venha a ser ensinar e aprender se (des)encontram. Nestes (des)encontros é que podem surgir, como nesse estudo, as relações estigmatizantes que culminam em resultados de fracassos e exclusões escolares. Sobre estes olhares (des)encontrados entre aluno e professor Senna (2007) destaca que:

\begin{abstract}
A instituição escolar não compreende [por aluno] qualquer sujeito em formação, universalmente legitimado pela ideologia de uma educação laica. Ao contrário, a tradição social imputa à escola um sujeito ideal, um aluno perfeito, um cidadão desenhado para o modelo de cultura científica idealizada. Conceitua este aluno de forma abstrata e ideativa, sequer fronteiriça à realidade transitória e relativa dos fatos reais, manipula-o também de forma abstrata, a partir de uma ordem de causalidade fundada na lógica cartesiana, registra-o de modo a condensar racionalmente o pensamento de forma linear tanto na aquisição do conhecimento quanto na aprendizagem da escrita (p. 164-165).
\end{abstract}

Diante de uma idealização do sujeito aluno, reforça-se a ideia de que o professor precisa estar em contato com essa diversidade presente no âmbito escolar e promover junto aos seus alunos a inclusão dos mesmos através da promoção de experiências escolares orientadas para o respeito à diversidade presente nas escolas e salas de aula.

Pode-se afirmar que a escola percorreu um longo caminho no sentido de promover a inclusão da adversidade presente em nossa sociedade, contudo, há ainda muitas considerações a serem tecidas rumo à um sistema educacional que proporcione à valorização da diferença e o respeito ao diferente. $\mathrm{O}$ educar pelo controle suplanta a possibilidade de uma escola inclusiva, no sentido, de explicar sem compreender as diferenças e fracassos daqueles que escapam à padronização escolar, mas ainda pela incoerência entre o discurso emancipatório e a prática pedagógica elitista.

Uma escola que se pretende inclusiva, ainda precisa desconstruir-se para repensar a concepção de educação que possa minimizar os efeitos de práticas que, ainda, vulnerabilizam muitos alunos em seus processos de formação.

Com as análises desse trabalho, espera-se que seja possível ampliar o debate sobre os desígnios da Educação que há tanto caminham na tentativa de oferecer condições de superação de uma realidade excludente e miserável. A escola é ainda, o espaço de construção de conhecimento que pode oferecer mudanças nas condições sociais, econômicas, culturais e educacionais excludentes aos que nela acreditam. Acredita-se, que

Revista Reflexão e Ação, Santa Cruz do Sul, v.19, n2, p.158-172, jul./dez. 2011 
dessa forma, seja possível ampliar o diálogo sobre os desígnios da Educação, que há tanto caminham na tentativa de oferecer condições de superação de uma realidade excludente e desigual.

\title{
STIGMA IN THE SCHOOL: THE PRACTICE OF THE CLASS COUNCIL
}

\begin{abstract}
The stigmatization observed at the interaction between teachers and students is the thematic of this paper. It present's the results from an ethnographic investigation at a basic public school at Rio de Janeiro city. For a school practice comprehension, especially between teachers and students, the participant observant was used at Class Council and classroom spaces. The analysis performed it follows that students that do not fit the normal standards imposed by school received a mark, a stigma, starting to be recognized for these assignments. It was also identified, at teachers speech, a control that made visible that mark to everyone who lives together with them. The results of this study provide clues to rethink the situation of vulnerability and exclusion that some students are exposed in the evaluation of the class councils, due to difficulties in their educational processes. It also offers the possibility of thinking about the difference by the difference in a school that effectively aims to be inclusive.
\end{abstract}

Keywords: Stigma; Control; Body; Class Council; Ethnography.

\section{Referências}

CASTRO, P. A. Controlar para quê? Uma análise etnográfica do controle na interação entre professor e aluno na sala de aula. 2006.187 f. Dissertação (Mestrado em Educação) Faculdade de Educação, Universidade do Estado do Rio de Janeiro, Rio de Janeiro, 2006.

DORON, R; PAROT, F. Dicionário de Psicologia. São Paulo: Ed. Ática, 1998.

FOUCAULT, M. Os anormais: curso no Collège de France (1974-1975). São Paulo: Martins Fontes, 2002.

Revista Reflexão e Ação, Santa Cruz do Sul, v.19, n2, p.158-172, jul./dez. 2011 
FOUCAULT, M. A verdade e as formas jurídicas. Rio de Janeiro: NAU, 1999.

FOUCAUlT, M. Os Anormais: curso no Collège de France (1974-1975). São Paulo: Martins Fontes, 2001.

FOUCAULT, M. Resumo dos Cursos do Collège de France (1970-1982). Rio de Janeiro: Jorge Zahar Ed., 1997.

FOUCAULT, M. Vigiar e Punir: nascimento das prisões. Petrópolis: Vozes, 1987.

GOFFMAN, E. Estigma: notas sobre a manipulação da identidade deteriorada. Rio de Janeiro: LTC, 2005.

HARGREAVES, A. A política emocional no fracasso e no êxito escolar. In: MARCHESI, A., GIL, C. H. (org.). Fracasso escolar uma perspectiva multicultural. Porto Alegre: ArtMed, 2004.

LAHIRE, B. As origens da desigualdade escolar. In: MARCHESI, Á. e GIL, C. H. (org.). Fracasso Escolar uma perspectiva multicultural. Porto Alegre: Artmed, 2004.

REVEL, J. Michel Foucault: conceitos essenciais. São Carlos: Claraluz, 2005.

RODRIGUES, A; ASMAR E. M. L.; JABLONSKI, B. Psicologia Social. $25^{\mathrm{a}}$ ed. Petrópolis, RJ: Vozes, 2007.

SENNA, L. A. G. (org.). Letramento: princípios e processos. Curitiba: Ibpex, 2007.

Data de recebimento: $15 / 08 / 2011$

Data de aceite: $21 / 11 / 2011$

Revista Reflexão e Ação, Santa Cruz do Sul, v.19, n2, p.158-172, jul./dez. 2011 